\title{
High Flow Nasal Cannula Could Be a Therapeutic Approach to Sleep Apnea Syndrome - Current Evidences
}

\section{Díaz-Lobato $\mathbf{S}^{*}$, Galarza-Jiménez, Barbero-Herranz $\mathbf{E}$ and Mayoralas-Alises $\mathbf{S}$}

Department of Respiratory Medicine, Ramón y Cajal Teaching Hospital, Madrid, Spain

*Corresponding author: Díaz-Lobato S, Pneumological Department Ramón y Cajal Teaching Hospital, Carretera de Colmenar Viejo, Km 9,100, 28034 Madrid, Spain, Tel: 003491336 8133; E-mail: sdiazlobato@gmail.com

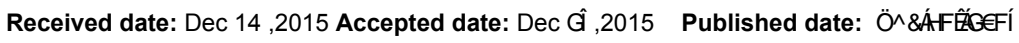

Copyright: $\odot 2016$ Lobato SD, et al. This is an open-access article distributed under the terms of the Creative Commons Attribution License, which permits unrestricted use, distribution, and reproduction in any medium, provided the original author and source are credited.

\begin{abstract}
High flow nasal cannula (HFNC) is a new therapeutic approach to patients with several forms of respiratory failure. Studies have shown that HFNC generates a low level of positive airway pressure, improves oxygenation, increases the end-expiratory lung volume, reduces airway resistance, increases functional residual capacity and alveolar recruitment and flushes nasopharyngeal dead space, thus helping to decrease the work of breathing. There is a better control of $\mathrm{FiO}_{2}$ and the gas humidification ensures a better patient tolerance and comfort. Due to a better mucociliary clearance, pulmonary defense mechanisms are restored. The low levels of pressure generated by HFNC may suggest that perhaps could play a role in the treatment of sleep apnea. Some studies have demonstrated a positive effect of HFNC on the apnea-hypopnea index showing us that HFNC could be an alternative to conventional treatment of obstructive sleep apnea in children and adults with fruitful results. We present a review of available evidence.
\end{abstract}

Keywords: High flow nasal cannula; HFNC; OSAS; Sleep apnea syndrome; Treatment

\section{Introduction}

High flow nasal cannula (HFNC) therapy allows us to provide a high flow up to 60 liters per minute associated with a reliable inspired oxygen fraction up to $100 \%$. The gas is delivered to the patient through a nasal cannula of larger diameter than usual and it is previously heated at body temperature ( 35 to 40 degree Celsius) and humidified, so that it has a better tolerability. This therapeutic approach has a lot of physiological effects which makes it a real active treatment for patients with respiratory failure both acute and chronic, more than a simple oxygen delivery system. Several studies have shown that HFNC generates a low level of positive airway pressure, improves oxygenation, increases the end-expiratory lung volume, reduces airway resistance, increases functional residual capacity and alveolar recruitment and flushes nasopharyngeal dead space, thus helping to decrease the work of breathing. There is a better control of $\mathrm{FiO}_{2}$ and the gas humidification ensures a better patient tolerance and comfort. Due to a better mucociliary clearance, pulmonary defense mechanisms are restored $[1,2]$. Several studies have shown its utility in patients with acute hypoxemic respiratory failure, in the post-extubation period, in palliative care, in patients with acute heart failure, in chronic airway diseases and its indications are still rising [3]. It is used in critical care areas, in the emergency department, in wards and it is been using at home in COPD patients [4]. It is increasingly common to find articles about the use of HFNC in other situations. One of these new areas of research is related to the use of HFNC in patients suffering of sleep apnea syndrome.

Obstructive sleep apnea syndrome (OSAS) is the most common sleep disorder. It is caused by an obstruction of the upper airway, which leads to several periods of shorteness of breath, sleep fragmentation and desaturation. Its main clinical manifestation is daytime somnolence that associated with mood disturbance and cognitive decline, deteriorates patient's life. It is also described that obstructive apneas may induce during sleep intermittent hypoxemia (up to $<60 \%$ ) and $\mathrm{CO}_{2}$ retention disrupting the normal response of autonomic and hemodynamic to sleep which is related to high blood pressure, stroke and cardiovascular risk [5].

Obstructive sleep apnea syndrome is a health problem increasingly known for its underdiagnosis by pulmonologist and pediatric pulmonologist. Awareness of this disease makes health professionals request more polygraphys or polysomnographys, increasing its prevalence in our field. The classic treatment of sleep apnea has been continuous positive airway pressure (CPAP) applied by nasal interface in most cases. In pediatric patients, the adenotonsillectomy is the treatment of choice for the presence of adenoid and tonsillar hypertrophy. When medical resources and/or surgical treatments are not effective or well tolerated, it is necessary to take into account others therapeutic alternatives. In this sense, HFNC as an alternative for sleep apnea patients is a challenge.

Low levels of pressure have been demonstrated when using HFNC. The positive pressure at the end of expiration (PEEP effect) created by HFNC, decreases airway resistance and produces alveolar recruiting [6]. PEEP is flow dependent and may also vary with the opened or closed position of the mouth and the cannula size. Pressures up to 7.5 $\mathrm{cm} \mathrm{H}_{2} \mathrm{O}$ at 60 liters per minute can be reached, depending on the series [2].

\section{Evidences}

McGinley et al. [7] have studied the effect of HFNC in twelve patients aged from 5 to 15 years with OSAS. Most of them were boys and had obesity, with or without adenotonsillectomy and some were already in treatment with CPAP (not tolerated). Two studies using polysomnography, one with and one without HFNC were made. In 
Citation: Díaz-Lobato S, Galarza-Jiménez, Barbero-Herranz E, Mayoralas-Alises S (2015) High Flow Nasal Cannula Could Be a Therapeutic Approach to Sleep Apnea Syndrome - Current Evidences. Gen Med (Los Angel) 3: 220. doi:10.4172/2327-5146.1000220

Page 2 of 2

patients who were treated with CPAP, there was a subanalysis in which HFNC and CPAP was compared. Also the effectiveness of REM and NREM periods were compared. No differences between CPAP and HFNC in the treatment of mild to severe obstructive apnea were found. Evening events with HFNC (regardless of NREM and REM periods and regardless adenotonsillectomy or not) decreased. They concluded that HFNC therapy in children with obstructive sleep apnea is effective and may be used as an alternative treatment of obstructive sleep apnea.

Most recently, Joseph et al. [8] have studied five children with obstructive sleep apnea without adenotonsillectomy. This small cohort showed the effectiveness of treatment with HFNC in children with severe sleep apnea. They conclude the need of further randomized studies to confirm this hypothesis.

In another study, McGinley et al. [9] have studied again the effectiveness of HFNC, this time in adults. Eleven adult patients were included, aged $49 \pm 5$ years with a body mass index $30 \pm 4.3 \mathrm{~kg} / \mathrm{m}^{2}$ and with sleep obstructive apnea ranging from mild to severe. HFNC was administered at 20 liters per minute and all patients underwent polysomnography with measurement of apnea/hypopnea index and arousals. Reduction of apnea/hypopnea index and of number of obstructive apneas and arousals was demonstrated in all subjects. Likewise the mechanism of action appears to be through an increase in end-expiratory pharyngeal pressure, which alleviated upper airway obstruction and improved ventilation. They conclude that the HFNC could be a good alternative option for the treatment of obstructive sleep apnea in adults.

\section{Conclusions}

HFNC therapy is increasingly used in other situations outside acute respiratory failure. Among its major effects it can be mentioned a positive pressure at the end of expiration (PEEP effect) reducing air resistance, changes in patient's ventilatory pattern, laundering $\mathrm{CO}_{2}$ by the reduction of dead space and alveolar recruiting [10]. The low levels of pressure generated by HFNC may suggest that perhaps could play a role in the treatment of sleep apnea. Some studies have demonstrated a positive effect of HFNC on the apnea-hypopnea index showing us that HFNC could be an alternative to conventional treatment of obstructive sleep apnea in children and adults with fruitful results. However, the number of patients recruited is small, and most are not randomized, so new lines of research are needed in this area to reinforce this hypothesis. The role of HFNC in OSAS patients remains a challenge.

\section{References}

1. Spoletini G, Alotaibi M, Blasi F, Hill NS (2015) Heated humidified highflow nasal oxygen in adults: mechanisms of action and clinical implications. Chest 148: 253-261.

2. Dysart K, Miller TL, Wolfson MR (2009) Research in high flow therapy: mechanisms of action. Respir Med 103: 1400-1405.

3. Gotera C, Díaz Lobato S, Pinto T, Winck JC (2013) Clinical evidence on high flow oxygen therapy and active humidification in adults; Next Document Rev Port Pneumol 19: 217-227.

4. Sotello D, Rivas M, Mulkey Z, Nugent K (2015) High-flow nasal cannula oxygen in adult patients. A narrative review. Am J Med Sci 349: 179-185.

5. Stansbury RC, Strollo PJ (2015) Clinical manifestations of sleep apnea. J Thorac Dis 7: 298-310.

6. McGinley B, Halbower A, Schwartz AR, Smith PL, Patil SP, et al. (2009) Effect of a High-Flow Open Nasal Cannula System on Obstructive Sleep Apnea in Children. Pediatrics 124: 179-88.

7. Groves N, Tobin A (2007) High flow nasal oxygen generates positive airway pressure in adult volunteers. Aust Crit Care 20: 126-31.

8. Joseph L, Goldberg S, Shitrit M, Picard E (2015) High-Flow Nasal Cannula Therapy for Obstructive Sleep Apnea in Children. J Clin Sleep Med 11: 1007-1010.

9. McGinley B, Patil SP, Kirkness JP, Smith PL, Schwartz AR, et al. (2007) A Nasal Cannula Can Be Used to Treat Obstructive Sleep Apnea. Am J Respir Crit Care Med 176: 194-200.

10. Díaz Lobato S, Alonso JM, Carratalá JM, Mayoralas S. High flow nasal cannula is not an oxygen therapy device. Rev Port Pneumol (in press). 